\title{
Muco-Submucosal Necrosis-Early Novel Complication following Intersphincteric Resections
}

Molnar $C^{*}$ and Butiurca VO

Chief of Surgery, Tîrgu-Mureș Emergency County Hospital, Romania

*Correspondling author: Călin Molnar, Associate Professor, Chief of Surgery, Surgical Clinic No. 1, TîrguMureș Emergency County Hospital, Romania

Received: September 09, 2016; Accepted: J anuary 26, 2017; Published: J anuary 31, 2017

\begin{abstract}
Intersphincteric Resection (ISR) is a relatively novel therapeutic option for patients with low rectal cancer. This type of surgery eliminates the need of a colostomy pouch but has its own set of complications. We present a short term complication following ISR that has now yet been documented.
\end{abstract}

Keywords: Muco-submucosal necrosis; Intersphincteric resection; Colostomy pouch

\section{Short Communication}

Ever since 1923 when William Ernes Miles described the abdominoperineal resection, a worldwide search for a better procedure for patients with rectal tumors began. Abdominoperineal resection (the first type of surgery for rectal cancer or anal cancer) is in itself an intervention with a negative impact on postoperative quality of life. The problems that arise following this type of intervention are unrelated to efficiency or postoperative complications although their rate is higher in low volume centers but rather to the sociopsychological impact on the patient [1]. The switch from a 'normal person' to a 'permanently needy' one caused by abnormal bowel emptying and the presence of a colostomy pouch led to the development of new specialties and to new types of surgery [2].

These are just some of the reasons that pushed surgeons to find techniques that improve the quality of life for patients with rectal tumors and create a type of surgery that eliminates the permanent need of a colostomy pouch. The Schiessel operation for low rectal cancer (intersphincteric resection or ISR), first disclosed in 1994 is nothing else but the bringing of high standards (technical and tactical) to the intervention promoted by Nicola Basso a century ago $[3,4]$.

During ISR, a transanal division of the rectum, with removal of part or the entire Internal Anal Sphincter (IAS) after total mesorectal excision, is performed, thus obtaining an adequate distal margin.

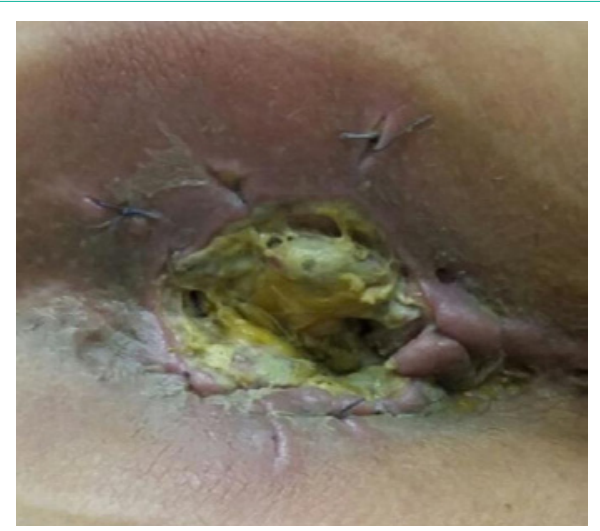

Figure 1: Muco-submucosal necrosis 10 days following open ISR.

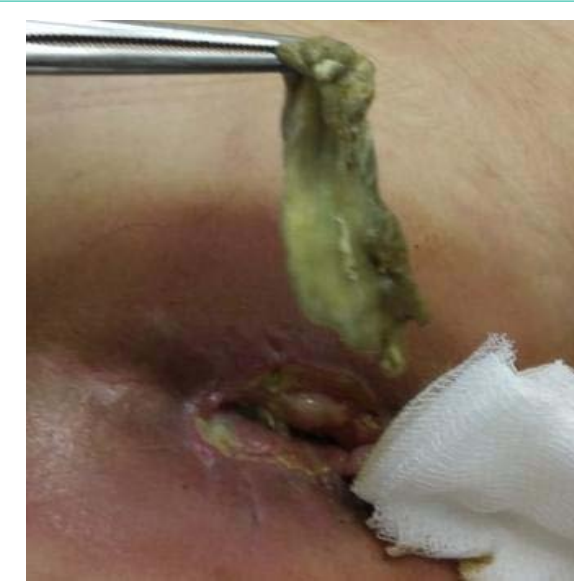

Figure 2: Removal of muco-submucosal sleeve using extraction forceps.

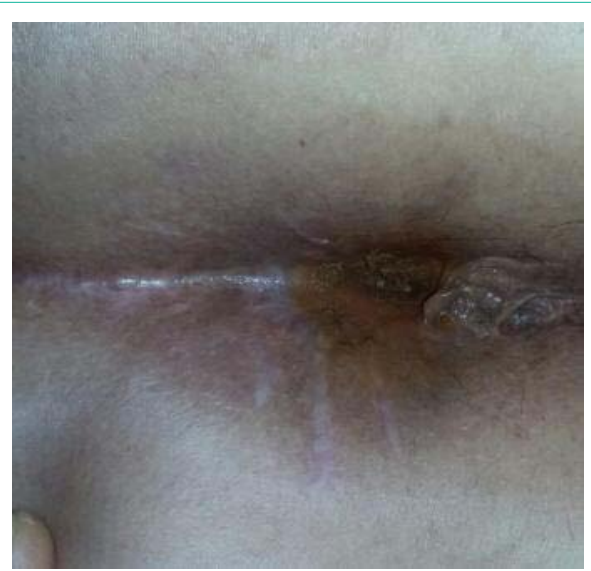

Figure 3: Three months postoperative after ISR.

Restoration of bowel continuity is achieved by performing a handsewn coloanal anastomosis.

Early postoperative complications associated with this intervention are known including complications associated with conventional surgery and laparoscopic surgery and are followed by a set of intervention specific complications that are not the subject of this communication.
Citation: Molnar C and Butiurca Vo. Muco-Submucosal Necrosis-Early Novel Complication following Intersphincteric Resections. Austin J Pathol Lab Med. 2017; 4(1): 1017. 
In this paper we signal an unusual, early, local complication following standard open ISR (7-10 days postoperatively), namely muco-submucosal necrosis of the pulled through colon.

The necrosis presents itself as a muco-submucosal sleeve (Figure 1) eliminated by the patient at the level of the 'new anal orifice' on average on the $10^{\text {th }}$ postoperative day. If not spontaneously eliminated it can be easily removed on an outpatient basis using extraction forceps (Figure 2). The extraction is not followed by a fistula or bleeding or a disturbance in sphincter continence. Under local topical treatment with antispasmodics within 2 months the defect turns into a fibrous tissue coated with colic mucosa with role incontinence (Figure 3 ).

Knowing this possible evolution following ISR we are obliged to signal it both to the patient and to surgeons performing this intervention.

\section{References}

1. Spanos CP. Intersphincteric resection for low rectal cancer: an overview. International journal of surgical oncology. 2012; 2012: 241512

2. Pai VD, De Souza A, Patil P, Engineer R, Arya S, Saklani A. Intersphincteric resection and hand-sewn coloanal anastomosis for low rectal cancer: Shortterm outcomes in the Indian setting. Indian Journal of Gastroenterology. $2015 ; 34: 23-28$

3. Schiessel R., Karner-Hanusch J, Herbst F, Teleky B, Wunderlich M. Intersphincteric resection for low rectal tumours. British Journal of Surgery. 1994; 81: 1376-1378.

4. Tsukada $\mathrm{Y}$, Ito M, Watanabe K, Yamaguchi K, Kojima M, Hayashi, et al. Topographic Anatomy of the Anal Sphincter Complex and Levator Ani Muscle as It Relates to Intersphincteric Resection for Very Low Rectal Disease. Diseases of the Colon \& Rectum. 2016; 59: 426-433.
Austin J Pathol Lab Med - Volume 4 Issue 1 - 2017

ISSN : 2471-0156 | www.austinpublishing group.com Molnar et al. (C) All rights are reserved
Citation: Molnar C and Butiurca VO. Muco-Submucosal Necrosis-Early Novel Complication following Intersphincteric Resections. Austin J Pathol Lab Med. 2017; 4(1): 1017. 